\title{
The membrane-bound mucins: From cell signalling to transcriptional regulation and expression in epithelial cancers
}

\author{
Nicolas Jonckheere, Isabelle Van Seuningen* \\ Q1 Inserm, U837, Jean-Pierre Aubert Research Centre, Team 5 "Mucins, epithelial differentiation and carcinogenesis", Place de Verdun, 59045 Lille cedex, France
}

\section{A R T I C L E I N F O}

\section{Article history:}

Received 17 July 2009

Accepted 30 September 2009

Available online $\mathrm{xxx}$

\section{Keywords:}

Mucin

Glycoprotein

Promoter structure-function

Cell signalling

Cancer

\section{Introduction}

Mucins belong to a heterogeneous family of large O-glycoproteins composed of a long peptidic chain called apomucin on which are linked hundreds of oligosaccharidic chains. Based on biochemical studies, mucins were initially defined as highmolecular weight (MW) molecules secreted by epithelia, able to form viscoelastic gels and responsible for rheological properties of mucus. Advent of molecular biology in the nineties allowed identification of high MW O-glycoproteins with structural characteristics of mucins which contained a transmembrane (TM) domain. Today, the family of membrane-bound mucins includes MUC1, MUC3A/B, MUC4, MUC12, MUC13, MUC15, MUC16, MUC17, MUC20 and MUC21 [1]. Among them, MUC1 and MUC4 are best characterized. Based on their structure and localization they are thought to play important biological roles in cell-cell and cell-extracellular matrix interactions, in cell signalling and in biological properties of cancer cells [2-6]. Moreover, their specific pattern of expression during the different steps of tumour progression toward

\footnotetext{
* Corresponding author. Tel.: +33 3202988 67; fax: +33 320538562 .

E-mail address: isabelle.vanseuningen@inserm.fr (I. Van Seuningen).
}

adenocarcinoma suggests that they play important roles in tumourigenesis and that they are specific markers of epithelial cancer cells. For all these reasons, membrane-bound mucins stay under intense investigation as both potent new biomarkers and therapeutic targets in epithelial cancers. On another hand, the family of secreted mucins, gel-forming components of viscoelastic mucus gels protecting the epithelia, includes mucins MUC2, MUC5AC, MUC5B, MUC6, and MUC19 [7]. Their main function is to participate in mucus formation by forming a tridimensional network via oligomerization domains to protect underlying epithelia against various injuries (inflammation, bacteria, virus, pollutants, pH, etc). MUC7 and MUC9 are smaller secreted mucins that do not oligomerize $[8,9]$.

A better understanding of the molecular structure of regulatory regions as well as mechanisms governing mucin expression is also mandatory if one wants to assign direct roles to mucins in carcinogenesis and better understand their influence on the biological properties of the tumour cell. Studies aiming at deciphering the signalling pathways will allow identification of potential therapeutic targets with the ultimate goal to restore normal mucin expression at the cell surface. Moreover the use of mucin promoters in gene-based therapy is under investigation and may provide new biological tools [2]. Animal models will also help define in vivo the 
roles of membrane-bound mucins in pathophysiological situations and help the scientific community determine whether mucin altered expression is a consequence of epithelium alteration or actively contributes to histological changes that promote carcinogenesis.

\section{MUC1 and MUC4 have a cell- and tissue-specific pattern of expression}

In this part of the review we will only describe the pattern of expression of membrane-bound mucins (Table 1 ). For expression of secreted mucins in the same cancers, see excellent following reviews [10-12].

\subsection{Respiratory tract}

The mucin gene expression pattern in normal airways and lung is complex [13]. Mucin genes are expressed in an array of epithelial cells exhibiting various phenotypes: MUC1 in submucosal glands and MUC1, MUC4, and MUC13 in the surface epithelium. In distal bronchioles, Clara cells express MUC1 and MUC4. The alveolar type II epithelial cells express the MUC1 glycoprotein whereas MUC4 gene expression is not detected in normal type II pneumocytes but is found in type II pneumocyte hyperplasia [13].

In atypical adenomatous hyperplasia $(\mathrm{AAH})$, the preinvasive lesion of peripheral lung adenocarcinomas, high level of MUC1 expression and very low levels of other mucins have been shown by immunohistochemistry (IHC) (Table 1). MUC1 expression was significantly decreased in the progression from AAH through nonmucinous bronchioloalveolar carcinoma (BAC) to invasive adenocarcinoma while depolarized MUC1 was significantly increased [14].

In hyperplasia (basal cell/goblet cell), metaplasia and dysplasia, the pattern of qualitative expression of mucin genes is similar to that determined for normal mucosae. Nevertheless quantitative variations of MUC4 expression levels are observed. No expression of $M U C 3$ is found in squamous lesions as in the normal respiratory surface epithelium [15].

Lung cancers are largely classified into two major groups based on their histopathologic differences: non-small-cell lung cancer (NSCLC), which is further divided into adenocarcinoma, squamous cell carcinoma, and large cell carcinoma; and smallcell lung carcinoma. The recent studies on mucin expression in lung cancer have been conducted to establish a relationship between the expression of any particular mucin and the histologic subtype [10,15-17]. Lung adenocarcinomas express mucin mRNAs which are expressed in normal respiratory mucosa (MUC1, MUC4) and MUC3 mRNAs which are not detected in normal lung by in situ hybridization (ISH) [16]. Nonmucinous type of BAC and non BAC type adenocarcinomas share the constant expression of MUC1 and MUC4, and variable expression of MUC3 [16,18]. Among adenocarcinomas, the mucinous type of BAC ( $m-B A C)$ has a particular pattern of mucin gene expression since all mucin genes are expressed. Coexpression of MUC1 and MUC3 is constant. Coexpression of MUC4 is very frequent. This complex but homogeneous expression pattern in m-BAC is in agreement with the great cellular homogeneity of this type of adenocarcinoma $[16,18]$.

\subsection{Gastro-intestinal tract}

\subsubsection{Oesophagus}

The normal oesophageal epithelium is considered as nonmucussecreting. MUC1 and MUC4 are the main mucins expressed both at the mRNA and protein levels in the stratified squamous epithelium $[19,20]$. Recently, expression of the membrane-bound mucin MUC20 has also been found, without any precision concerning staining location [21].

\section{Table 1}

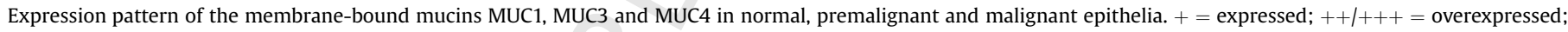
$\downarrow=$ decrease of expression. All data presented are at the protein level unless RT-PCR (mRNA) is indicated.

\begin{tabular}{|c|c|c|c|}
\hline & Normal & Metaplasia/Hyperplasia/Dysplasia & Cancer \\
\hline Lung & $\begin{array}{l}\text { Surface epithelial cells MUC1+, } \\
\text { MUC4+ } \\
\text { Submucosal gland MUC1+ } \\
\text { Clara cells MUC1+, MUC4+ } \\
\text { Alveolar type II MUC1+ }\end{array}$ & $\begin{array}{l}\text { Atypical adenomatous hyperplasia } \\
\text { (AAH) MUC1 }+++\end{array}$ & $\begin{array}{l}\text { Lung adenocarcinoma MUC1+, MUC4+ } \\
\text { Nonmucinous bronchoalveolar carcinoma } \\
\text { (BAC) MUC1 } \downarrow \text {, MUC4+ }\end{array}$ \\
\hline Oesophagus & $\begin{array}{l}\text { Squamous epithelial cells MUC1+, } \\
\text { MUC4+ }\end{array}$ & $\begin{array}{l}\text { Barrett's oesophagus MUC4 } \downarrow \text {, MUC1 n.d. } \\
\text { (conflicting reports) }\end{array}$ & $\begin{array}{l}\text { Squamous cell cancer MUC1 }+ \text {, MUC4 }+ \\
\text { Adenocarcinoma MUC1 }+++ \text { (conflicting reports), MUC4+++ }\end{array}$ \\
\hline Stomach & MUC1+ & $\begin{array}{l}\text { Intestinal metaplasia; MUC1 } \downarrow \\
\text { (good prognosis), } \\
\text { MUC3+++ (bad prognosis) }\end{array}$ & \\
\hline Small intestine & $\begin{array}{l}\text { Brünner's gland MUC1+, MUC4+ } \\
\text { Duodenum MUC1+ (RT-PCR) } \\
\text { Columnar cells MUC4+ } \\
\text { Vater's ampulla MUC1+, MUC4+ }\end{array}$ & & $\begin{array}{l}\text { Small intestine adenocarcinoma MUC1 }+++ \\
\text { (poor differentiation) } \\
\text { Ampullary adenocarcinoma MUC1 } 1++ \\
\text { (poor prognosis) }\end{array}$ \\
\hline Colon & $\begin{array}{l}\text { Columnar cells MUC4+ } \\
\text { Goblet cells MUC4+ }\end{array}$ & $\begin{array}{l}\text { Low-grade dysplasia MUC3+++ } \\
\text { (early stage marker) }\end{array}$ & Adenocarcinoma MUC1+++ (late stage marker), MUC4 $\downarrow$ \\
\hline Pancreas & Ductal cells MUC1+ & $\begin{array}{l}\text { Pancreatic intraepithelial neoplasia; } \\
\text { PanIN1A MUC1++, MUC4+; PanIN3 } \\
\text { MUC1++; MUC4++ } \\
\text { Intraductal papillary mucinous neoplasm } \\
\text { MUC1+++ (bad prognosis) }\end{array}$ & Adenocarcinoma MUC1 +++ , MUC4 +++ \\
\hline $\begin{array}{l}\text { Hepatobiliary } \\
\text { tract }\end{array}$ & MUC1 weak, MUC3+++ & & $\begin{array}{l}\text { Gallbladder carcinoma MUC1+ } \\
\text { Cholangiocarcinoma MUC1+, MUC4+ } \\
\text { Intrahepatic cholangiocarcinoma (ICC) MUC1++ }\end{array}$ \\
\hline
\end{tabular}


MUC1 and MUC4 were found in the mid layers of the stratified squamous epithelium, whereas their relevant protein core was predominantly found in the more superficial layers. MUC1 and MUC4 are predominantly found at the membrane epithelial cells. However cytoplasmic expression can be found. In squamous cell carcinoma, MUC1 and MUC4 expression is maintained as in normal tissues, mainly on the cell membrane of surface epithelial cells, but also in the cytoplasm in several cases [22-26]. Mucin gene expression greatly varies and accompanies cell differentiation in the process of Barrett's oesophagus characterized by incomplete intestinal metaplasia (IM) with presence of goblet cells, and expresses a mixture of gastric (MUC5AC, MUC6) and intestinal (MUC1, MUC2, MUC3) mucins [20,27-30]. MUC1 and MUC4 mucin genes are also expressed in cardiac and fundic metaplasia whereas MUC3 is scarcely detected. MUC1 is expressed in both superficial and in deeper glands of Barrett's metaplasia. MUC1 gene expression is not found in IM. MUC3 is focally expressed in the superficial epithelium in non-goblet cells adjacent to goblet cells. Mild MUC4 expression is detected in the basal region of columnar cells of the surface epithelium and in the crypt epithelium [19,20]. In our experience this staining concerns both goblet and non-goblet cells and is predominantly cytoplasmic [31,32]. To sum up, between normal mucosa and Barrett's oesophagus, mRNA and protein studies conversely reported higher expression of MUC3 and lower expression of MUC4 [20,33,34]. Reports concerning MUC1 mucin gene expression are conflicting. Both over/neo-expression and decrease of expression have been described [19,20,33,35,36]. During the progression from dysplasia to adenocarcinoma, downregulation of MUC3 is observed whereas MUC4 is raised [19,20,29,33,35]. Reports regarding MUC1 are still conflicting. Immunohistochemical expression of MUC1 and MUC3 showed that both were absent in high-grade dysplasia, whereas they were reexpressed in adenocarcinoma. In most studies, increase of MUC1 between dysplasia and adenocarcinoma was reported [20,35,37,38]. However, Endo et al. [30] found that patients expressing MUC1 showed a decreased level of MUC1 between dysplasia and adenocarcinoma. Between metaplasia and adenocarcinoma, MUC3 was mostly down-regulated. MUC4 expression mostly rose from metaplasia to dysplasia and adenocarcinoma. To sum up, MUC1, MUC3 and MUC4 are observed in 22-100\%, 33-66\% and $42-78 \%$ of oesophageal adenocarcinoma [19,20,29,30,3537,39]. MUC1 immunohistochemical staining was either membranous [29,37], cytoplasmic [39] or both [31]. Several authors have now proposed that mucin genes may be considered as reliable phenotypic markers to follow the metaplastic process that leads to Barrett's adenocarcinoma [19,20,34,40]. However, clinical impact of MUC1 and MUC4 expression has been recently evaluated and showed no prognostic value in Barrett's associated oesophageal adenocarcinoma [32]. Recent works in our laboratory showed that MUC1 and MUC4 are targets of bile acids (taurocholic (TC), deoxycholic (DC), taurodeoxycholic (TDC), taurochenodeoxycholic (TCDC) and glycocholic (GC) acids, and sodium glycocholate (GNa)) which high gastric concentration has been observed in patients with Barrett's oesophagus. It has been suggested that incomplete IM may be a response to reflux of gastroduodenal contents and in particular to bile acids. This effect is mediated via PI3K signalling pathway and involves HNF- $1 \alpha$ and HNF- $4 \alpha$ transcription factors direct interaction with MUC1 and MUC4 promoters [31,41,42]

\subsubsection{Stomach}

Normal stomach mucosa is characterized by expression of MUC1, MUC5AC and MUC6 mucins [12,43,44]. Apical MUC1 expression occurs in the superficial and foveolar epithelium and mucous neck zone cells of gastric mucosa. MUC3 and MUC4 are generally absent from normal gastric mucosa [45]. Mucins appeared as key molecules for the classification of IM of the stomach. Complete IM is characterized by expression of MUC2 in goblet cells and decreased expression of MUC1, MUC5AC and MUC6 [46]. Patients who maintain high immunoreactivity for anti-MUC1 antibody have a better prognosis, whereas those with an increase in anti-MUC3 immunoreactivity have a poorer prognosis, as judged by tumour size, serosal invasion, and metastasis [47] (Table 1).

\subsubsection{Small intestine}

MUC1 is detected in Brünner's glands [48] (Table 1). By RT-PCR, all mucins including MUC1 are detected in normal duodenum, whereas all mucins but MUC2 are found in Vater's ampulla [49]. In the normal duodenum, MUC1 apomucin is not detected whereas MUC4 is found in columnar cells and Brünner's glands [49]. In Vater's ampulla, MUC1 mucin is absent whereas MUC4 is expressed in columnar cells [49]. MUC17 is expressed throughout the entire intestinal tract with the highest expression in the duodenum $[50,51]$ and was shown to be expressed at the membrane surface in an N-glycosylation dependent manner [52]. In mouse jejunum, Malmberg and collaborators showed a strong MUC17 expression in the brushborder that is dependent of Pdzk1 protein via a PDZ interaction motif in the C-terminal tail of MUC17 [53]

MUC1 is differentially expressed in ampullary adenocarcinoma compared to normal duodenum and its overexpression was confirmed by IHC on tissue microarrays [54]. MUC1 was reported in 26/38 ampullary adenocarcinomas and was related to lymph node metastasis, advanced stage of TNM (T: tumour, N: nodes, M: metastasis) and to a poorer prognosis [55]. As in other localizations, invasive micropapillary carcinomas of the ampullo-pancreatobiliary region display a reversal of cell polarity with MUC1 labelling observed in the stroma-facing surfaces of the micropapillary clusters [56]. A recent study on 30 small intestinal adenocarcinomas (SIAs) showed frequent focal staining of MUC1. Moreover, poorly differentiated SIAs tend to express MUC1 more frequently than well- and moderately-differentiated SIAs [57].

\subsubsection{Colon}

The two membrane-bound mucins MUC3 and MUC4 are expressed by columnar and colonic goblet cells [58-60] (Table 1). MUC3 is expressed in the supra- and perinuclear cytoplasm of goblet cells and also in columnar cells, being more abundant in the superficial epithelium compared with the crypt bases of the colon $[58,59]$. According to an mRNA analysis, MUC3 is expressed to a lower level in colon compared to small intestine [59]. MUC1 was inconsistently observed at the apical membrane within the crypt base in normal colon, its detection being enhanced by periodate oxydation [61]. MUC12 membrane mucin is also expressed in normal colon [62]. A recent study about expression of membranebound mucins in normal colon confirmed high expression of MUC1, MUC3, MUC4, MUC13 and MUC12 [38]. They were also found in normal and tumour rectum with similar expression levels.

Analysis of human tissues demonstrated that some mucinassociated peptides were significantly decreased or increased during the adenoma-carcinoma sequence (Table 1). Indeed, MUC1 is a late stage marker of the adenoma-carcinoma sequence, being highly expressed in high-grade dysplasia, whereas MUC3 is an early stage marker, being mostly detected in low-grade dysplasia [38,63]. Interestingly a study also showed that MUC1 expression did not differ between de novo carcinomas and those developing from adenomas and that its expression was found in the course of colorectal carcinoma development when p53 is overexpressed and apoptosis prominent [64]. MUC12 membrane-bound mucin was found consistently down-regulated in colon carcinomas (6/15) [62] as well as MUC4 and MUC13 [38,65]. MUC17 was shown to be expressed in colon cancer cells [53]. 


\subsection{Pancreas}

MUC1 is the main membrane-bound mucin expressed in normal pancreas (Table 1). The labelling concerns acinar cells, at the cytoplasmic level, and ductal cells at the apical level [66]. Therefore, MUC1 has been used as a marker of ductal cells in several studies $[67,68]$.

Despite controversial initial results, no MUC4 transcript or apomucin are found in normal pancreatic tissues [66]. However a number of nonneoplastic duct lesions such as atrophic ducts, or ducts in the setting of an inflammatory reaction, show expression of MUC4.

Clinical, pathological and genetics studies have identified three different preneoplastic lesions of the duct as precursors of pancreatic ductal adenocarcinoma (PDAC). These lesions are pancreatic intraepithelial neoplasia (PanIN), intraductal papillary mucinous neoplasm (IPMN) and mucinous cystic neoplasm (MCN). Among these lesions PanIN are the most frequent and best characterized both at the morphological and molecular levels [69].

Pancreatic carcinogenesis is characterized by an altered pattern of mucin expression at different stages of tumour progression. Membrane-bound mucin production has been detected as early as PanIN1A stage: neoexpression of MUC4, increase of MUC1 expression (Table 1). The PanIN3 stage, previously named in situ carcinoma, is characterized by an increase of MUC4 and MUC1 expression and occurrence of MUC3 [70].

A gradual expression of MUC4 during pancreatic carcinogenesis has been demonstrated by IHC: $17 \%$ of PanIN1A, 36\% of PanIN2 and $85 \%$ of PanIN3 express MUC4 [71]. In true PDAC, the prevalence of MUC4 apomucin expression reaches $83-89 \%[71,72]$. These results are in agreement with gene expression profile studies which showed that MUC4 belongs to the most differentially expressed genes in PDAC [73]. The MUC1 mucin is more frequently expressed by PanIN lesions (around $70 \%$ of the cases) compared to normal pancreas. Around $80 \%$ of PDAC samples still express MUC1 [74]. IPMN is thought to be another precursor of PDAC. It originates in the main pancreatic duct and is characterized by a massive dilatation of the ducts or cyst formation and hypersecretion of mucins. Usually IPMN has a good clinical course but $10-20 \%$ of IPMN are invasive carcinomas with worse prognosis [75]. IPMN expressing MUC1 correspond to invasive carcinoma with a short survival rate and bad prognosis whereas those that express MUC5AC correspond to slow-growing adenoma with good prognosis.

\subsection{Hepatobiliary tract}

Strong expression of MUC3 mRNA in all biliary epithelial cells and hepatocytes, and weak expression of MUC1 in biliary epithelial cells has been described $[48,70,76]$ (Table 1 ). No expression of MUC4 mRNA was detected. By IHC, expression of MUC1 and MUC4 apomucins, was found in cholangiocarcinomas whereas gallbladder carcinomas express MUC1. The increased expression of MUC1 and MUC4 is related to the aggressive behaviour of carcinoma cells and poorer prognosis [77]. Intrahepatic cholangiocarcinoma (ICC) can be classified into mass-forming type, periductal-infiltrating type or intraductal-growth type, with a better prognosis for the intraductal-growth type [77,78]. MUC1 is expressed in all types in more than 70\% of tumours [78]. Massforming type ICC is associated with higher MUC1 expression [79]. In biliary tract carcinoma (BTC), high expression of MUC1 is associated with positive detection of carcinomatous cells by bile juice cytology [80]. In patients with biliary obstruction, MUC4 expression in bile and MUC5AC expression in serum are highly specific markers for BTC [81]. In gallbladder carcinomas, MUC1 expression increases with histological dedifferentiation [82]. Biliary papillomatosis is a rare disease that is characterized by multiple numerous papillary adenomas in the biliary tree, in majority of cases associated with biliary papillary or mucinous adenocarcinoma [83]. Marked expression of MUC1 is rather frequent in biliary papillomatosis with carcinoma and intrahepatic biliary papillary carcinoma compared with biliary papillomatosis alone [84].

\section{Mucins as diagnostic and/or prognostic factors in epithelial cancers}

From expression studies described in the first part of this review it is obvious that mucin gene and protein regulation is profoundly altered in epithelial cancers (Table 1). Early abnormal detection of mucins during carcinogenetic sequence or mucins showing oncofoetal pattern of expression raises the question of whether these molecules may be useful diagnostic markers for the clinician. Moreover, prognostic value of mucins has been evaluated in many carcinomas and in some cases already proved useful [85]. However, their prognostic value is often better when included in a panel of biomarkers. Mucins are also used as phenotypic markers to classify tumours as well as to identify primary site of metastatic tumours.

MUC1 and MUC4 are also often associated with tumour progression and metastasis, even though opposite activity has been described in upper and lower aerodigestive tracts. For most of the cancers prospective studies are required to decipher some conflicting data about the utility of mucins as biomarkers. The problems of the specificity of the antibodies, of the standardized immunostaining protocols and strict criteria for staining interpretation are also important issues still to improve. Use of gene expression profiling, which allows investigation of thousands of genes at once, in the clinic is also being debated at this time and the relevance of molecular signatures to patient care still questionable [86]. The interpretation of these molecular signatures remains a challenge but their use to phenotype tumours is very promising although still in its early-age [87]. Next to studies about molecular pathogenesis of cancer, pre-clinical mouse models of cancer potentially represent effective strategies for cancer diagnosis and treatment [88]. The biggest challenge with animal models being to find the best model that reproduces all the morphological and molecular events found in humans.

Overexpression of MUC1 represents a marker of aggressive biological behaviour in nonsmall lung, gastric, colorectal carcinomas. Some studies already use MUC1 as a therapeutic target in immunotherapy or gene-based therapy $[2,89,90]$. MUC1 could also be used as a prognostic marker. In gastric cancer, patients who maintain a high reactivity for MUC1 have a better prognosis [91]. Moreover, MUC1 expression in IPMN is related to a worse prognosis whereas MUC5AC secreted mucin is associated with a better survival rate [92].

In general MUC4 expression in carcinomas depends on histological type and differentiation grade of the tumour. MUC4 overexpression is associated with more aggressiveness and increased metastases in breast cancer, extrahepatic bile duct carcinoma, and cholangiocarcinoma [93-95]. Conversely, improved patient survival was associated with MUC4 expression in ovarian cancer, mucoepidermoid carcinoma of the salivary glands, and squamous cell carcinoma of the upper aerodigestive tract [96-98]. In NSCLCs, MUC4 expression was associated with an improved survival in early stage adenocarcinomas. In the lung its diagnostic value was also demonstrated to distinguish between epithelial mesothelioma and lung adenocarcinoma [99]. Thus the relationship between MUC4 expression and tumour behaviour is organ-dependent. This means that correlation to patient survival will have to be assessed in every type of carcinoma where MUC4 is overexpressed. 


\section{Transcriptional regulation of MUC1 in epithelial cancer cells}

Because membrane-bound mucins are often overexpressed in carcinomas as described in the first part of this review, investigators have started to study their transcriptional regulation in order to use them (i) as targets and control their expression and (ii) as biological tools in human gene therapy.

MUC1 transcriptional regulation has been extensively studied in mammary cancer cells, an organ in which its overexpression is routinely used as a tumour marker and thought to contribute to disease progression.

The MUC1 promoter is GC-rich and contains a typical TATA box located 25 nucleotides upstream of the transcriptional start site (Fig. 1) [100]. $2.9 \mathrm{~kb}$ of the $5^{\prime}$-flanking region has been published so far (GenBank accession numbers: L06162 and X69118). It is characterized by numerous binding sites for specificity protein-1 (Sp1), activator protein-1 (AP-1), AP-2, AP-3, nuclear factor -1 (NF-1), Estrogen Receptor (ER), "milk binding protein factor" and STAT (Signal Transducers and Activators of Transcription) transcription factors [100-102]. In MCF-7 breast cancer cell line, a $45 \mathrm{kDa}$ unidentified protein interacts with the $-505 /-485$ region and is necessary for MUC1 transcription [101].

The $-743 /-1$ region was shown to be sufficient to drive transcriptional activity of a reporter gene in MUC1-expressing epithelial cell lines. The $-150 /-60$ region, which contains one Sp1 ciselement $(-99 /-90)$ and one E-box called E-MUC1 $(-86 /-64)$, is crucial to observe MUC1 tissue-specific expression (Fig. 1) [103].
The $-101 /-89$ region interacts with two transcription factors: Sp1 and SpA. SpA recognizes Sp members consensus sequence GGGCGG but is distinct from the other members (Sp3, Sp4). In breast epithelial cancer cells, SpA, acts as a transcription inhibitor and regulates MUC1 expression level. In carcinomas, increase of MUC1 expression could be the result of an increase of Sp1 binding. Sp1/ SpA ratio seems important in MUC1 transcriptional regulation since these two transcription factors compete for the same binding site [104].

Three regions called M-PMR1 (Mucin-Purin pyrimidine Mirror Repeat, -641/-615), M-PMR2 $(-253 /-237)$ and M-PMR3 $(-133 /-102)$ have been identified in MUC1 promoter [105,106]. These purine-rich regions $(G+A)$ on one strand and pyrimidinerich $(T+C)$ on the other strand are characterized by a perfect mirror repeat element and are found to be associated with the formation of an H-DNA helix which could be involved in transcription regulation. A $27 \mathrm{kDa}$ protein interacting with these regions was identified [107,108]. SpA binding specificity is influenced by M-PMR3 element which adjoins it but M-PMR3 had a very modest inhibitory effect on MUC1 transcriptional activity [106].

MUC1 promoter contains cis-elements for inflammatory signalling pathways such as interferon- $\gamma$ or cytokines. In T47D breast cancer cell line, inside the promoter region, four transcriptional STAT sites $(-90,-75,-55$ and -35$)$ were characterized close to the TATA- and GC-boxes. STAT sites are downstream elements of interferon signalling pathway. In breast cancer cell lines, proinflammatory factors interferon- $\gamma$ (IFN- $\gamma$ ) and interleukin-6 (IL-6) stimulated transcription of a luciferase reporter construct under

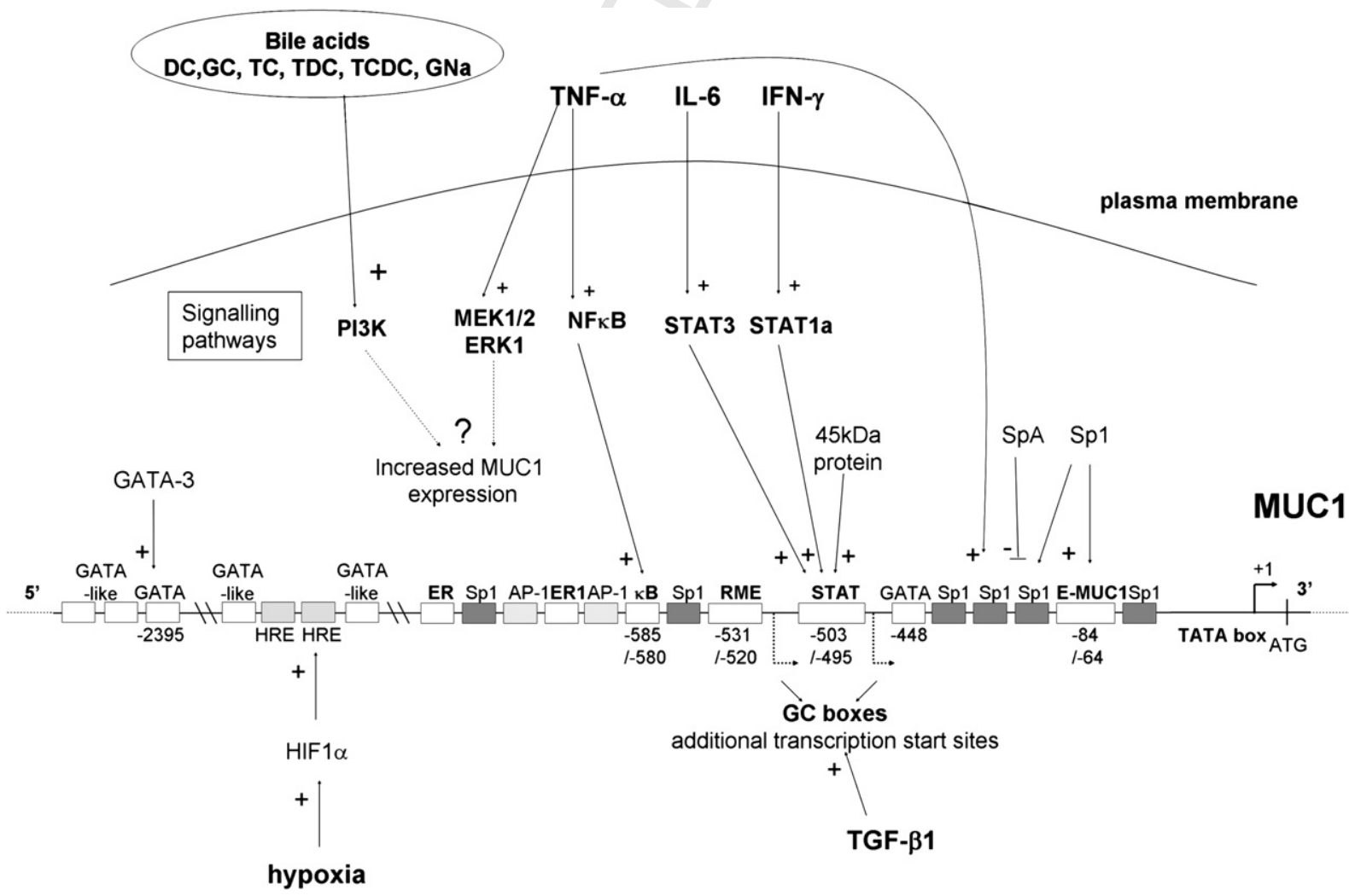

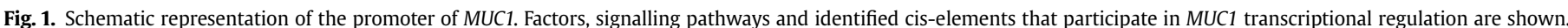

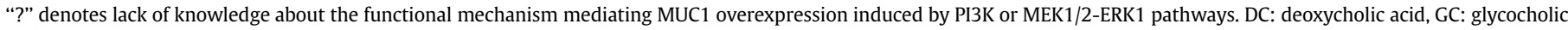

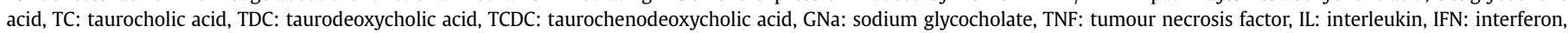

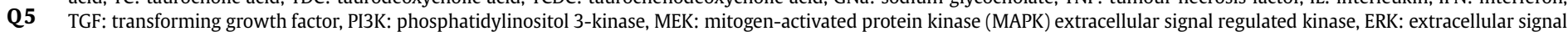

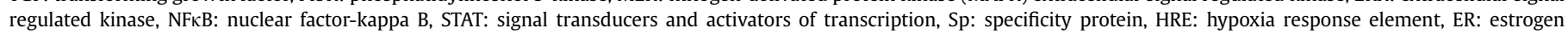
receptor, AP: activator protein, RME: responsive mucin element. 
the control of the $-722 /-1$ region of MUC1 promoter (Fig. 1) [102]. An STAT cis-element localized at -503 mediates this activation since its mutation abolished stimulation of the reporter by these cytokines. Furthermore, STAT mutation decreased promoter basal activity in unstimulated cells. IFN- $\gamma$ and IL- 6 were shown to respectively activate STAT1 and STAT3, which then, interact with their cis-element at $-503 /-485$. These results strongly suggest that STAT binding is an important mechanism in the overexpression of MUC1 in tumour cells [102].

Regulation of MUC1 by TGF- $\beta 1$ growth factor is driven by two additional transcriptional start sites $(-520$ and -130$)$ [109]. Authors suggested that some GC-boxes positioned at the $3^{\prime}$-end of the promoter may drive transcription independently of the TATA box. Knockdown experiments showed that GATA-3 transcription factor (TF) is a mediator of transcriptional upregulation of MUC1 in MCF7 and T47D cells via a GATA-3 functional binding site [110].

Shirotani et al. have shown that a region between nucleotides -531 and -520 of $5^{\prime}$-flanking region of MUC1 promoter was sufficient to observe transcriptional activity under normal colon conditioned medium (NCCM) conditions, a situation known to stimulate mucin production by human colon carcinoma cells [111]. This sequence was called RME (Responsive Mucin Element), and seems to interact with an unknown $70 \mathrm{kDa}$ protein [112].

In A549 human lung adenocarcinoma cells proinflammatory cytokine tumour necrosis factor- $\alpha$ (TNF- $\alpha$ ) stimulates expression of MUC1 by increasing de novo transcription in a mitogen-activated protein kinase kinase (MEK)1/2-extracellular signal-regulated kinase-1 (ERK1) dependent manner. MUC1 promoter activation also requires an $\mathrm{Sp} 1$ element located between nucleotides -99 and -90 [113]. In clear renal cell carcinomas (cRCC), MUC1 is directly regulated by Hypoxia Inducible Factor (HIF)- $1 \alpha$ via HIF responsible elements (HRE) located at $-1488 /-1485$ and at $-1510 /-1507$. That upregulation affects the invasive and migration properties of renal cancer cells [114].

In vivo studies using transgenic mice have confirmed results obtained in vitro. To this aim, the group of Taylor-Papadimitriou has developed two strains of transgenic mice containing (i) a $10.6 \mathrm{~kb}$ genomic fragment consisting of the exons and introns of MUC1 flanked by $1.6 \mathrm{~kb}$ of the $5^{\prime}$-sequence and $1.9 \mathrm{~kb}$ of the $3^{\prime}$-sequence of the gene [115] and (ii) a transgene in which $1.4 \mathrm{~kb}$ of MUC1 promoter was fused to MUC1 cDNA [116]. The results showed that MUC1 is a compact gene and that the first 1400 nucleotides of MUC1 promoter contain all the cis-elements necessary (i) for epithelialspecific expression of the gene in vivo and (ii) for the upregulation of MUC1 expression observed at lactation and in tumourigenic process.

\section{MUC1 epigenetic regulation in cancer cells}

The term of epigenetics refers to a heritable change in gene expression that is driven by mechanisms other than alteration of nucleotidic sequence. Epigenetic changes include methylation of DNA, methylation and acetylation of histones and very recently regulation by miRNA. These mechanisms are often altered in pathological processes. Alterations of expression include both silencing and overexpression of mucin genes while promoters of mucin genes share a GC-rich structure and, for most of them, contain a CpG island, two structures characteristics in favour of epigenetic regulation [117]. MUC1 gene is characterized by the presence of a $\mathrm{CpG}$ island in a large transcribed region that consists of 60 -bp tandemly repeated units, each containing one SmaI restriction site. Evaluation of the methylation status of various regions of the MUC1 gene by Zrihan-Licht and collaborators using the methylation-sensitive enzymes SmaI and XmaI showed that, in peripheral blood leukocytes that do not express MUC1, the 60-bp repeat array was completely methylated, whereas the same sequences were entirely unmethylated in DNA from MUC1overexpressing breast tumour tissue. Hypomethylation within the repeat array was also observed in other epithelial tissues that express MUC1 at much lower levels than those seen in breast cancer tissue, demonstrating that hypomethylation of the tandem repeat array was an absolute requirement for MUC1 gene expression in epithelial tissues [118]. Influence of methylation in MUC1 silencing was also showed in prostate cancer cells by using inhibitor of methylation 5-aza-2'-deoxycitidine [119]. In the same study, influence of histone deacetylation was observed after cell treatment with sodium butyrate but no information regarding direct involvement of histone modifications in MUC1 gene regulation is available at this time. Lately, Yamada and collaborators have identified 9 hypermethylated cytosine residues tightly associated with H3 lysine 9 (H3-K9) dimethylation in MUC1 non-expressing cell lines [120].

\section{Transcriptional regulation of MUC4 in epithelial cancer cells}

$3.7 \mathrm{~kb}$ of MUC4 5'-flanking region have been characterized so far (GenBank accession number: AF241535) and four transcriptional initiation sites have been described: one localized in the proximal promoter at -199 and three in the distal promoter at $-2603,-2604$ and -2605 from the translational start site (Fig. 2) [121]. The proximal promoter is TATA-less and mainly composed of GC-rich domains that are potential binding sites for $\mathrm{Sp} 1$ but also for the CACCC box binding protein [121]. Furthermore, a very high density of binding sites for factors known to initiate transcription in TATAless promoter (Sp1, CACCC box, glucocorticoid receptor element, AP-1, polyomavirus Enhancer Activator-3 (PEA3) and Med-1) was found inside the proximal promoter [122-125]. The distal promoter is characterized by a TATA box located at $-2672 /-2668$. Numerous putative binding sites for Sp1, AP-1, AP-4, GATA and cyclic adenosine monophosphate (CAMP) responsive element binding protein (CREB) transcription factors were found. MUC4 promoters also contain numerous putative binding sites for transcription factors involved in proteine kinase A (PKA), PKC, cAMP signalling pathways, in inflammation and in intestinal and respiratory differentiation.

Pancreatic cancer cells have been the major model for MUC4 regulation since MUC4 is not expressed in normal pancreas, is neoexpressed in early neoplastic precursor stage of pancreatic carcinogenesis with constant increase till adenorcarcinoma (see Section 2.3). In that model, MUC4 was shown to be regulated by a wide range of specific factors (Fig. 2). Tumour suppressor AP-2 down-regulates MUC4 expression at both protein and transcriptional levels via two AP-2 cis-elements located in the $-475 /-238$ region of the promoter [72]. The Ets family member PEA3 is implicated in a wide range of cellular processes such as differentiation, proliferation and transformation [126] and was shown to upregulate MUC4 expression in synergy with c-Jun and Sp1 whereas PEA3 represses the transcriptional activity of ErbB2 promoter [127]. Inflammatory pathway IFN- $\gamma$ increases MUC4 expression via STAT-1 upregulation [128]. TGF- $\beta$ which possesses both tumour-suppressive and oncogenic activities [129] is a strong activator of MUC4 expression. TGF- $\beta$ regulation involves a cooperation between Smad 2 and Smad4 transcription factors, and Smad4 binding to seven Smad Binding Elements (SBE) located along proximal and distal promoters [130]. When Smad4 is mutated and inactive, TGF- $\beta$ is still able to activate MUC4 expression via mitogen-activated protein kinase (MAPK), phosphoinositide-3 kinase (PI3K) and PKA signalling pathways [130]. All-trans-retinoic acid (RA) treatment increases MUC4 expression via retinoic acid 


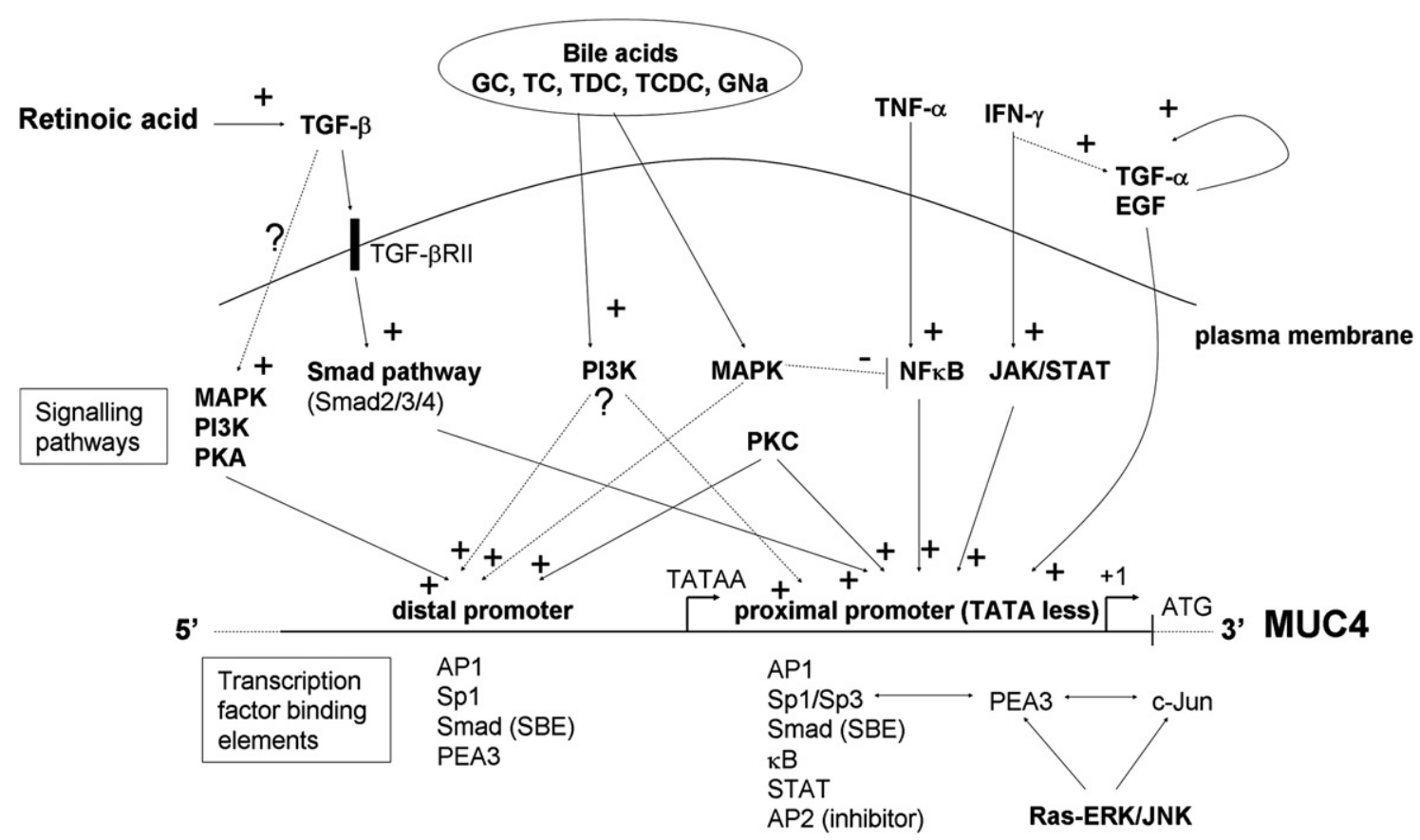

Cell differentiation of gut endoderm derived tissues (distal promoter)

CDX-1, CDX-2

HNF- $1 \alpha$, HNF- $1 \beta$

HNF- $4 \alpha$, HNF- $4 \gamma$

FOXA1, FOXA2

GATA-4, GATA-5, GATA-6

Fig. 2. Schematic representation of promoters of MUC4. Factors, signalling pathways known to regulate MUC4 expression are shown. Transcription factors binding elements are listed. "?" denotes lack of knowledge about the functional mechanism mediating activation of MAPK, PI3K and PKA pathways by TGF- $\beta$. GC: glycocholic acid, TC: taurocholic acid, TDC: taurodeoxycholic acid, TCDC: taurochenodeoxycholic acid, GNa: sodium glycocholate, TGF: transforming growth factor, EGF: epidermal growth factor, TNF: tumour necrosis factor, IL: interleukin, IFN: interferon, PI3K: phosphatidylinositol 3-kinase, MAPK: mitogen-activated protein kinase, MEK: MAPK-extracellular signal regulated kinase, PKA: protein kinae A, NFKB: nuclear factor-kappa B, STAT: signal transducers and activators of transcription, JAK: Janus kinase, Sp: specificity protein, AP: activator protein, SBE: Smad binding element, PEA3: polyomavirus Enhancer Activator-3, JNK: Jun N-terminal kinase, Cdx: caudal-related homeobox, HNF: hepatocyte nuclear factor, FOXA: forkhead box A.

receptor- $\alpha(\operatorname{RAR}-\alpha)$. That upregulation is a consequence of the increase of expression of TGF- $\beta 2$ regulating MUC4 expression in an autocrine manner [131]. IFN- $\gamma$ and RA can synergize at the transcriptional level to induce MUC4 expression in pancreatic tumour cells [132]. MUC4 expression is negatively regulated by chloride channel called cystic fibrosis transmembrane conductance regulator (CFTR) that is implicated in multiple cellular functions. CFTR mutation carrier status is correlated with early-onset of pancreatic adenocarcinoma [133]. It was observed that CFTR was downregulated in pancreatic cancer cells and negatively correlated with MUC4 [134].

MUC4 regulation has also been studied in oesophageal cancer cells since this mucin was shown to be overexpressed during the metaplasia/dysplasia/adenocarcinoma sequence characteristic of oesophageal adenocarcinoma (see Section 2.2.1). Studies focused on MUC4 regulation by bile acids since they are incriminated to promote tumour progression in oesophageal cancer cells. Bile acids positively regulate MUC4 expression via PI3K signalling pathway and binding of HNF- $1 \alpha$ transcription factor to MUC4 promoter [31,41].

MUC4 regulation has also been studied in intestinal cells since previous works had shown early expression of MUC4 mRNA in embryonic gut $[135,136]$. In vitro studies indeed showed that hepatocyte nuclear factors (HNF-1/-4), forkhead box A (FOXA1/A2), GATA-4/-5/-6, and caudal-related homeobox (CDX-1/-2) TFs which control cell differentiation of gut endoderm derived-tissues during embryonic development, are also regulators of MUC4 and may act in synergy [137].
Altogether, these results indicate that MUC4 expression is extremely complex and tightly regulated and involves many signalling pathways including inflammatory- and tumour- associated factors (Fig. 2). This of course is in favors of an important role for MUC4 mucin during development, epithelial differentiation, but also in epithelial repair and cancer.

\section{MUC4 epigenetic regulation in cancer cells}

The $5^{\prime}$-flanking region of MUC4 is characterized by a high $\mathrm{G}+\mathrm{C}$ content, up to $72 \%$ almost exclusively concentrated in the proximal promoter and the $5^{\prime}$-Untranslated Region (5'-UTR), and the presence of two CpG islands of 135 and 146 bp, respectively, both located in proximal and distal promoters at $-2370 /-2236$ and $-738 /-593[138]$.

Influence of histone deacetylation on MUC4 silencing was first assessed in our laboratory in the MUC4 non-expressing pancreatic cancer cell line PANC-1 using cell treatment with trichostatine A (TSA) [130] and later shown in prostate cancer cells using cell treatment with sodium butyrate by Singh and collaborators [119]. This group also showed the influence of DNA methylation in regulating MUC4 in these cells by using 5-aza-2'-deoxycytidine (5-aza).

In order to better understand how constant increase of MUC4 during the different steps of pancreatic carcinogenesis could be regulated, we undertook a thorough study of MUC4 chromatin status in pancreatic cancer cells expressing different levels of MUC4 mucin. Our recent studies indicates that MUC4 proximal and distal 
promoters, which possess each a $\mathrm{CpG}$ island, are heavily methylated whether the gene is expressed or not in the cells. On the contrary, MUC4 5'-UTR shows a methylation profile, that was directly correlated to the level of MUC4 expression in the cells. Hypermethylation of MUC4 $5^{\prime}$-UTR is associated with establishment of a repressive histone code, including deacetylation and methylation of histone H3 [138]. Methylation of Sp1 binding sites located in the proximal promoter and the 5'-UTR dramatically impairs MUC4 activation by Sp1, whereas methylation of the adjacent CPG site upstream of the $5^{\prime}$-UTR has no effect. DNA methyltransferase (DNMT)-3A, DNMT3B and histone deacetylase-3 (HDAC3) were identified as potent regulators of MUC4 endogenous expression via a direct binding to its 5'-UTR [138].

From these studies, we proposed the following model of MUC4 epigenetic regulation: in non-expressing cells, MUC4 silencing would be mediated by DNA methylation and histone deacetylation at the $5^{\prime}$-UTR, whereas in low expressing cells progressive demethylation would allow low expression of MUC4, and finally in highexpressing cells selective hypomethylation and permissive chromatin would allow binding of essential transcription factors such as Sp1 and full transcription of MUC4 gene [138]. This model may reflect constant upregulation of MUC4 in epithelial carcinogenesis in different organs such as oesophagus, pancreas, lung or colon. Yamada and collaborators recently confirmed the CpG methylation on MUC4 5'-UTR using MassARRAY ${ }^{\circledR}$ compact system and showed two additional methylated cytosines associated with control of MUC4 gene expression in ten cancer cell lines [139].

Globally, regulation of MUC1 and MUC4 genes is complex and involves a wide array of signalling pathways. Common growth factors (EGF, TGF- $\beta$ ) or proinflammatory pathways (IFN- $\gamma$, TNF- $\alpha$ ) are regulators for both genes. In a similar manner, MUC1 and MUC4 are members of the class of epigenetically controlled genes. However, a concerted regulation of the two genes remains hypothetical. Such regulations also raise the questions of whether these two mucins can compensate for each other or if they act separately as they are differentially expressed during carcinogenesis.

\section{Regulation of other membrane-bound mucins in cancer cells}

To date, very little is known about regulation of the other

The 5'-flanking region of $M U C 3 A$ gene has been analysed. MUC3A transcripts initiate from multiple start sites along a region spanning around 180 nucleotides. MUC3A promoter lacks a cognate TATA box. Analysis using TFSEARCH and MatInspector softwares showed that MUC3A promoter contains potential binding sites for transcription factors implicated in the regulation of intestinal genes (CDX-2, GATA, USF, CACCC and HNF-1) [140]. Moreover, mRNA level of MUC3 is increased by overexpression of GATA-5 in both COS-7 and 293T cells [141]. Most of the expression studies do not differentiate MUC3A from MUC3B. Phorbol esters, such as phorbol 12myristate 13-acetate (PMA), which modulate diverse cellular responses through signal transduction pathways like PKC pathway, cancer cells. The MUC3 upregulation is inhibited after treatment with protein synthesis inhibitors or Calphostin C, a highly specific inhibitor of PKC. These changes were associated with increase of matrix metalloproteinase (MMP) activity as well as by increase in the invasive and motility properties of cells. Therefore, PKC signalling pathway may regulate MUC3 expression and modulate the invasive and metastatic properties of colon cancer cells. It was also shown that the secreted thiol-activated cytolysin listeriolysin $\mathrm{O}$ (LLO), responsible for $L$. monocytogenes-induced high-molecular membrane-bound mucins. caused upregulation of mRNA levels of MUC3 in HM3 human colon glycoproteins (HMGs) exocytosis, leads to MUC3 and MUC12 increased expression in colon cancer cells HT29-MTX [142].

Helicobacter pylori causes gastric preneoplasia and neoplasia. cDNA microarray assays showed that MUC13 is down-regulated after $H$. pylori infection and upregulated in placebo control group on gastric biopsies suggesting the potential use of MUC13 as a marker of gastric cancer risk [143].

MUC16 is upregulated at mRNA and protein levels following an $\mathrm{RA}$ treatment of human conjunctival epithelial (HCjE) cells. The RAassociated upregulation of MUC16 appears to be mediated by secretory phospholipase A(2) group IIA (sPLA(2)-IIA) [144]. RT-PCR and western blot experiments also showed that MUC16 gene expression is upregulated $48 \mathrm{~h}$ after addition of dexamethasone in human corneal epithelial cells. Treatment with glucocorticoid receptor antagonist RU38486 inhibits the change of MUC16 by dexamethasone; thus, the effect of dexamethasone on MUC16 expression is mediated by glucocorticoid receptors [145].

MUC17 upstream region is an intergenic region located in between MUC12 and MUC17 genes that contains VDR/RXR, GATA, $\mathrm{NF} K \mathrm{~B}$ and $\mathrm{Cdx}-2$ response elements. That 1146 bp region shows a strong enhancer and a significant promoter activity in AsPC-1 and HPAF pancreatic cancer cell lines [51].

\section{Perspectives}

In the future, new technologies will bring new clinical tools. In that sense, detection of mucin epitopes or motifs in biological fluids, establishment and access to high throughput studies of mucin epigenetic status are very promising.

To the clinical point of view, an ideal marker implicates noninvasive and rapid procedures of detection. Therefore, several laboratories develop the idea of mucins as circulating markers in the blood or markers associated with biological fluids such as pancreatic juice. In pancreatic cancer, recent work showed that MUC1 mRNA was detected in pancreatic juice during the development of high-grade PanIN to intraductal carcinoma. That quantification has a high potential for preoperative diagnosis of pancreatic cancer [146]. Moreover, Jhala et al. used MUC4 as a biomarker in fine-needle aspirate (FNA) samples and showed that MUC4 could help distinguish ductal epithelial cells from pancreatic adenocarcinoma [147]. Therefore, Klapman and Malafa proposed that screening high risk individuals (familial pancreatic cancer, hereditary pancreatic cancer syndrome, cigarette smoking or early-age onset of diabetes) by FNA remains so far the only practical approach to detect precancerous or cancerous changes in the pancreas at a phase during which surgery will have a high chance to cure [148]

Rapid and systematic evaluation of epigenetic status of mucin genes in tumour cells by pyrosequencing may also provide clinicians with new early detection tools to screen for the presence of cancer, in which mucin genes are epigenetically expressed.

Recently microRNAs (miRNA) were described as a new epigenetic regulation of mammalian genes. MiRNA are small non-coding RNAs that negatively regulate gene expression in a sequencespecific manner. MiRNAs are essential regulators of various biological processes such as proliferation, differentiation, development or cell death [149]. So far, there is no direct evidence of mucin regulation by miRNA but one cannot exclude a targeting of mucins long $3^{\prime}$-UTRs. Preliminary studies from our laboratory suggest that mucin $3^{\prime}$-UTRs contain conserved miRNA target elements [150]. Thus, further analysis will be conducted to demonstrate the role of miRNA in the ever-increasing complexity of mucin gene regulation in epithelial cancers.

The ultimate goal is to establish tumour identification for each patient that will allow adaptation of treatment and therapy. Mucins are among the specific epithelial markers that may be included in 
such ID next to a panel of biomarkers that will become more and more precise as detection technologies improve and will allow rapid analysis of the whole genome.

\section{Acknowledgments}

Nicolas Jonckheere is the recipient of a post-doctoral fellowship from Institut National du Cancer (INCa). This work is funded by Ligue Nationale Contre le Cancer (IVS, Equipe Labellisée LIGUE 2008).

\section{References}

[1] N. Jonckheere, I. Van Seuningen, The ever growing family of membranebound mucins, in: I. Van Seuningen (Ed.), The Epithelial Mucins: Structure/ Function. Roles in Cancer and Inflammatory Diseases. Research Signpost, Kerala, India, 2008, pp. 17-38.

[2] N. Jonckheere, I. Van Seuningen, The membrane-bound mucins: how large O-glycoproteins play key roles in epithelial cancers and hold promise as biological tools for gene-based and immunotherapies. Crit. Rev. Oncog 14 (2008) 177-196.

[3] K.L. Carraway 3rd, M. Funes, H.C. Workman, C. Sweeney, Contribution of membrane mucins to tumor progression through modulation of cellular growth signaling pathways. Curr. Top. Dev. Biol. 78 (2007) 1-22.

[4] C.L. Hattrup, S.J. Gendler, Structure and function of the cell surface (tethered) mucins. Annu. Rev. Physiol. 70 (2008) 431-457.

[5] P.K. Singh, M.A. Hollingsworth, Cell surface-associated mucins in signal transduction. Trends Cell Biol. 16 (2006) 467-476.

[6] G. Theodoropoulos, K.L. Carraway, Molecular signaling in the regulation of mucins. J. Cell Biochem. 102 (2007) 1103-1116.

[7] J.L. Desseyn, V. Gouyer, D. Tetaert, Architecture of the gel-forming mucins. in: I. Van Seuningen (Ed.), The Epithelial Mucins: Structure/Function. Roles in Cancer and Inflammatory Diseases. Research Signpost, Kerala, India, 2008, pp. 1-16.

[8] S.K. Linden, P. Sutton, N.G. Karlsson, V. Korolik, M.A. McGuckin, Mucins in the mucosal barrier to infection. Mucosal Immunol. 1 (2008) 183-197.

[9] D.J. Thornton, K. Rousseau, M.A. McGuckin, Structure and function of the polymeric mucins in airways mucus. Annu. Rev. Physiol. 70 (2008) 459-486

[10] M.C. Copin, M.P. Buisine, L. Devisme, et al, Normal respiratory mucosa, precursor lesions and lung carcinomas: differential expression of human mucin genes. Front. Biosci. 6 (2001) D1264-D1275.

[11] A.P. Corfield, D. Carroll, N. Myerscough, C.S. Probert, Mucins in the gastrointestinal tract in health and disease. Front. Biosci. 6 (2001) D1321-D1357.

[12] A.P. Corfield, N. Myerscough, R. Longman, P. Sylvester, S. Arul, M. Pignatelli, Mucins and mucosal protection in the gastrointestinal tract: new prospects for mucins in the pathology of gastrointestinal disease. Gut 47 (2000) 589-594

[13] M.C. Copin, M. Perrais, I. Van Seuningen, Mucins in the pathophysiological lung. Expression and roles in immuno- and gene-based therapies. in: I. Van Seuningen (Ed.), The Epithelial Mucins: Structure/Function. Roles in Cancer and Inflammatory Diseases. Research Signpost, Kerala, India, 2008, pp. 109-124.

[14] H. Awaya, Y. Takeshima, M. Yamasaki, K. Inai, Expression of MUC1, MUC2 MUC5AC, and MUC6 in atypical adenomatous hyperplasia, bronchioloalveolar carcinoma, adenocarcinoma with mixed subtypes, and mucinous bronchioloalveolar carcinoma of the lung. Am. J. Clin. Pathol. 121 (2004) 644-653.

[15] M.C. Copin, L. Devisme, M.P. Buisine, et al., From normal respiratory mucosa to epidermoid carcinoma: expression of human mucin genes. Int. J. Cancer 86 (2000) 162-168.

[16] M.C. Copin, M.P. Buisine, E. Leteurtre, et al., Mucinous bronchioloalveolar carcinomas display a specific pattern of mucin gene expression among primary lung adenocarcinomas. Hum. Pathol. 32 (2001) 274-281.

[17] A. Lopez-Ferrer, V. Curull, C. Barranco, et al., Mucins as differentiation markers in bronchial epithelium. Squamous cell carcinoma and adenocarcinoma display similar expression patterns. Am. J. Respir. Cell Mol. Biol. 24 (2001) 22-29.

[18] K. Tsuta, G. Ishii, J. Nitadori, et al., Comparison of the immunophenotypes of signet-ring cell carcinoma, solid adenocarcinoma with mucin production, and mucinous bronchioloalveolar carcinoma of the lung characterized by the presence of cytoplasmic mucin. J. Pathol. 209 (2006) 78-87.

[19] P. Guillem, V. Billeret, M.P. Buisine, et al., Mucin gene expression and cell differentiation in human normal, premalignant and malignant esophagus. Int. J. Cancer 88 (2000) 856-861.

[20] G.S. Arul, M. Moorghen, N. Myerscough, D.A. Alderson, R.D. Spicer, A.P. Corfield, Mucin gene expression in Barrett's oesophagus: an in situ hybridisation and immunohistochemical study. Gut 47 (2000) 753-761.

[21] T. Higuchi, T. Orita, S. Nakanishi, et al., Molecular cloning, genomic struc ture, and expression analysis of MUC20, a novel mucin protein, upregulated in injured kidney. J. Biol. Chem. 279 (2004) 1968-1979.
[22] C. Labouvie, J.C. Machado, F. Carneiro, et al., Differential expression of mucins and trefoil peptides in native epithelium, Barrett's metaplasia and squamous cell carcinoma of the oesophagus. J. Cancer Res. Clin. Oncol. 125 (1999) 71-76.

[23] Z.B. Song, S.S. Gao, X.N. Yi, et al., Expression of MUC1 in esophageal squamous-cell carcinoma and its relationship with prognosis of patients from Linzhou city, a high incidence area of northern China. World J. Gastroenterol. 9 (2003) 404-407.

[24] M. Sagara, S. Yonezawa, K. Nagata, et al., Expression of mucin 1 (MUC1) in esophageal squamous-cell carcinoma: its relationship with prognosis. Int J. Cancer 84 (1999) 251-257.

[25] H. Kijima, O. Chino, G. Oshiba, et al., Immunohistochemical MUC1 (DF3 antigen) expression of human esophageal squamous cell carcinoma. Anticancer Res. 21 (2001) 1285-1289.

[26] U. Flucke, T.K. Zirbes, W. Schroder, et al., Expression of mucin-associated carbohydrate core antigens in esophageal squamous cell carcinomas. Anticancer Res. 21 (2001) 2189-2193.

[27] M.B. Piazuelo, S. Haque, A. Delgado, J.X. Du, F. Rodriguez, P. Correa, Phenotypic differences between esophageal and gastric intestinal metaplasia. Mod. Pathol. 17 (2004) 62-74.

[28] C. Gulmann, O.A. Shaqaqi, A. Grace, et al., Cytokeratin 7/20 and MUC1, 2, $5 A C$, and 6 expression patterns in Barrett's esophagus and intestinal metaplasia of the stomach: intestinal metaplasia of the cardia is related to Barrett's esophagus. Appl. Immunohistochem. Mol. Morphol. 12 (2004) 142-147.

[29] J.N. Glickman, P.L. Blount, C.A. Sanchez, et al., Mucin core polypeptide expression in the progression of neoplasia in Barrett's esophagus. Hum. Pathol. 37 (2006) 1304-1315.

[30] T. Endo, K. Tamaki, Y. Arimura, et al., Expression of sulfated carbohydrate chain and core peptides of mucin detected by monoclonal antibodies in Barrett's esophagus and esophageal adenocarcinoma. J. Gastroenterol. 33 (1998) 811-815.

[31] G. Piessen, N. Jonckheere, A. Vincent, et al., Regulation of the human mucin MUC4 by taurodeoxycholic and taurochenodeoxycholic bile acids in oesophageal cancer cells is mediated by hepatocyte nuclear factor 1alpha. Biochem. J. 402 (2007) 81-91.

[32] G. Piessen, A. Wacrenier, N. Briez, J.P. Triboulet, I. Van Seuningen, C. Mariette, Clinical impact of MUC1 and MUC4 expression in Barrett's-associated oesophageal adenocarcinoma, J Clin Pathol, in press.

[33] D.A. Bax, J. Haringsma, A.W. Einerhand, et al., MUC4 is increased in high grade intraepithelial neoplasia in Barrett's oesophagus and is associated with a proapoptotic Bax to Bcl-2 ratio. J. Clin. Pathol. 57 (2004) 1267-1272.

[34] C. Warson, J.H. Van De Bovenkamp, A.M. Korteland-Van Male, et al., Barrett's esophagus is characterized by expression of gastric-type mucins (MUC5AC, MUC6) and TFF peptides (TFF1 and TFF2), but the risk of carcinoma development may be indicated by the intestinal-type mucin, MUC2. Hum. Pathol. 33 (2002) 660-668.

[35] S.C. Burjonrappa, S. Reddimasu, Z. Nawaz, X. Gao, P. Sharma, B. Loggie Mucin expression profile in Barrett's, dysplasia, adenocarcinoma sequence in the esophagus. Indian J. Cancer 44 (2007) 1-5.

[36] U. Flucke, E. Steinborn, V. Dries, et al., Immunoreactivity of cytokeratins (CK7, CK20) and mucin peptide core antigens (MUC1, MUC2, MUC5AC) in adenocarcinomas, normal and metaplastic tissues of the distal oesophagus, oesophago-gastric junction and proximal stomach. Histopathology 43 (2003) 127-134.

[37] C.N. Chinyama, R.E. Marshall, W.J. Owen, et al., Expression of MUC1 and MUC2 mucin gene products in Barrett's metaplasia, dysplasia and adenocarcinoma: an immunopathological study with clinical correlation. Histopathology 35 (1999) 517-524.

[38] L.M. Packer, S.J. Williams, S. Callaghan, D.C. Gotley, M.A. McGuckin, Expression of the cell surface mucin gene family in adenocarcinomas. Int. J. Oncol. 25 (2004) 1119-1126.

[39] C. Gulmann, I. Counihan, A. Grace, et al., Cytokeratin 7/20 and mucin expression patterns in oesophageal, cardia and distal gastric adenocarcinomas. Histopathology 43 (2003) 453-461.

[40] G. Piessen, C. Mariette, I. Van Seuningen, Mucin expression and regulation in oesophageal cancer: new molecular targets in cancer progression from Barrett's oesophagus to adenocarcinoma? in: I. Van Seuningen (Ed.), The Epithelial Mucins: Structure/Function. Roles in Cancer and Inflammatory Diseases Research Signpost, Kerala, India, 2008, pp. 169-182.

[41] C. Mariette, M. Perrais, E. Leteurtre, et al., Transcriptional regulation of human mucin MUC4 by bile acids in oesophageal cancer cells is promoterdependent and involves activation of the phosphatidylinositol 3-kinase signalling pathway. Biochem. J. 377 (2004) 701-708.

[42] C. Mariette, G. Piessen, E. Leteurtre, B. Hemon, J.P. Triboulet, I. Van Seuningen. Activation of MUC1 mucin expression by bile acids in human esophageal adenocarcinomatous cells and tissues is mediated by the phosphatidylinositol 3-kinase. Surgery 143 (2008) 58-71.

[43] S.B. Ho, A.M. Roberton, L.L. Shekels, C.T. Lyftogt, G.A. Niehans, N.W. Toribara, Expression cloning of gastric mucin complementary DNA and localization of mucin gene expression. Gastroenterology 109 (1995) 735-747.

[44] I. Van Seuningen, E. Leteurtre, Mucin expression and regulation in the gastro-intestinal tract. Actors of carcinogenesis? in: I. Van Seuningen (Ed.), The Epithelial Mucins: Structure/Function. Roles in Cancer and Inflammatory Diseases Research Signpost, Kerala, India, 2008, pp. 183-210.

1086

1087
1088 
[45] J.R. Jass, Mucin core proteins as differentiation markers in the gastrointestinal tract. Histopathology 37 (2000) 561-564.

[46] E. Silva, A. Teixeira, L. David, et al., Mucins as key molecules for the classification of intestinal metaplasia of the stomach. Virchows Arch. 440 (2002) 311-317.

[47] J.Y. Wang, C.T. Chang, J.S. Hsieh, et al., Role of MUC1 and MUC5AC expressions as prognostic indicators in gastric carcinomas. J. Surg. Oncol. 83 (2003) 253-260

[48] M.P. Buisine, L. Devisme, P. Degand, et al., Developmental mucin gene expression in the gastroduodenal tract and accessory digestive glands. II. Duodenum and liver, gallbladder, and pancreas. J. Histochem. Cytochem. 48 (2000) 1667-1676

[49] F.P. Paulsen, D. Varoga, A.R. Paulsen, A. Corfield, M. Tsokos, Prognostic value of mucins in the classification of ampullary carcinomas. Hum. Pathol. 37 (2006) 160-167.

[50] J.R. Gum Jr., S.C. Crawley, J.W. Hicks, D.E. Szymkowski, Y.S. Kim, MUC17, a novel membrane-tethered mucin. Biochem. Biophys. Res. Commun. 291 (2002) 466-475

[51] N. Moniaux, W.M. Junker, A.P. Singh, A.M. Jones, S.K. Batra, Characterization of human mucin MUC17. Complete coding sequence and organization. J. Biol. Chem. 281 (2006) 23676-23685.

[52] J.J. Ho, R.S. Jaituni, S.C. Crawley, S.C. Yang, J.R. Gum, Y.S. Kim, N-glycosylation is required for the surface localization of MUC17 mucin. Int. J. Oncol. 23 (2003) 585-592

[53] E.K. Malmberg, T. Pelaseyed, A.C. Petersson, et al., The C-terminus of the transmembrane mucin MUC17 binds to the scaffold protein PDZK1 that stably localizes it to the enterocyte apical membrane in the small intestine. Biochem. J. 410 (2008) 283-289.

[54] N.T. Van Heek, A. Maitra, J. Koopmann, et al., Gene expression profiling identifies markers of ampullary adenocarcinoma. Cancer Biol. Ther. 3 (2004) 651-656.

[55] W. Tang, Y. Inagaki, N. Kokudo, et al., KL-6 mucin expression in carcinoma of the ampulla of Vater: association with cancer progression. World J. Gastroenterol. 11 (2005) 5450-5454.

[56] S. Khayyata, O. Basturk, N.V. Adsay, Invasive micropapillary carcinomas of the ampullo-pancreatobiliary region and their association with tumorinfiltrating neutrophils. Mod. Pathol. 18 (2005) 1504-1511.

[57] M.Q. Zhang, F. Lin, P. Hui, Z.M. Chen, J.H. Ritter, H.L. Wang, Expression of mucins, SIMA, villin, and CDX2 in small-intestinal adenocarcinoma. Am. J. Clin. Pathol. 128 (2007) 808-816.

[58] S.K. Chang, A.F. Dohrman, C.B. Basbaum, et al., Localization of mucin (MUC2 and MUC3) messenger RNA and peptide expression in human normal intestine and colon cancer. Gastroenterology 107 (1994) 28-36.

[59] S.B. Ho, G.A. Niehans, C. Lyftogt, et al., Heterogeneity of mucin gene expression in normal and neoplastic tissues. Cancer Res. 53 (1993) 641-651.

[60] C.M. Winterford, M.D. Walsh, B.A. Leggett, J.R. Jass, Ultrastructural localization of epithelial mucin core proteins in colorectal tissues. J. Histochem. Cytochem. 47 (1999) 1063-1074.

[61] Y. Ohe, Y. Hinoda, T. Irimura, K. Imai, A. Yachi, Expression of sulfated carbohydrate chains detected by monoclonal antibody $91.9 \mathrm{H}$ in human gastric cancer tissues. Jpn. J. Cancer Res. 85 (1994) 400-408.

[62] S.J. Williams, M.A. McGuckin, D.C. Gotley, H.J. Eyre, G.R. Sutherland, T.M. Antalis, Two novel mucin genes down-regulated in colorectal cancer identified by differential display. Cancer Res. 59 (1999) 4083-4089.

[63] S.E. Baldus, F.G. Hanisch, Biochemistry and pathological importance of mucin-associated antigens in gastrointestinal neoplasia. Adv. Cancer Res. 79 (2000) 201-248

[64] T. Tanimoto, S. Tanaka, K. Haruma, et al., MUC1 expression in intramucosal colorectal neoplasms. Possible involvement in histogenesis and progression. Oncology 56 (1999) 223-231.

[65] S.J. Williams, D.H. Wreschner, M. Tran, H.J. Eyre, G.R. Sutherland, M.A. McGuckin, Muc13, a novel human cell surface mucin expressed by epithelial and hemopoietic cells. J. Biol. Chem. 276 (2001) 18327-18336.

[66] C. Balague, G. Gambus, C. Carrato, et al., Altered expression of MUC2, MUC4, and MUC5 mucin genes in pancreas tissues and cancer cell lines. Gastroenterology 106 (1994) 1054-1061.

[67] D.A. Cano, N.S. Murcia, G.J. Pazour, M. Hebrok, Orpk mouse model of polycystic kidney disease reveals essential role of primary cilia in pancreatic tissue organization. Development 131 (2004) 3457-3467.

[68] C.E. Pierreux, A.V. Poll, C.R. Kemp, et al., The transcription factor hepatocyte nuclear factor- 6 controls the development of pancreatic ducts in the mouse. Gastroenterology 130 (2006) 532-541.

[69] R.H. Hruban, M. Goggins, J. Parsons, S.E. Kern, Progression model for pancreatic cancer. Clin. Cancer Res. 6 (2000) 2969-2972.

[70] I. Van Seuningen, E. Leteurtre, P. Pigny, Mucins in pancreas and hepato-biliary tract. Expression, regulation, biomarkers and therapy. in: I. Van Seuningen (Ed.), The Epithelial Mucins: Structure/Function. Roles in Cancer and Inflammatory Diseases. Research Signpost, Kerala, India, 2008, pp. 233-248.

[71] M.J. Swartz, S.K. Batra, G.C. Varshney, et al., MUC4 expression increases progressively in pancreatic intraepithelial neoplasia. Am. J. Clin. Pathol. 117 (2002) 791-796.

[72] V. Fauquette, S. Aubert, S. Groux-Degroote, et al., Transcription factor AP2alpha represses both the mucin MUC4 expression and pancreatic cancer cell proliferation. Carcinogenesis 28 (2007) 2305-2312.
[73] C.A. Iacobuzio-Donahue, R. Ashfaq, A. Maitra, et al., Highly expressed genes in pancreatic ductal adenocarcinomas: a comprehensive characterization and comparison of the transcription profiles obtained from three major technologies. Cancer Res. 63 (2003) 8614-8622.

[74] G.E. Kim, H.I. Bae, H.U. Park, et al., Aberrant expression of MUC5AC and MUC6 gastric mucins and sialyl Tn antigen in intraepithelial neoplasms of the pancreas. Gastroenterology 123 (2002) 1052-1060.

[75] K.C. Conlon, Intraductal papillary mucinous tumors of the pancreas. J. Clin. Oncol. 23 (2005) 4518-4523.

[76] B. Vandenhaute, M.P. Buisine, V. Debailleul, et al., Mucin gene expression in biliary epithelial cells. J. Hepatol. 27 (1997) 1057-1066.

[77] M. Sasaki, H. Ikeda, Y. Nakanuma, Expression profiles of MUC mucins and trefoil factor family (TFF) peptides in the intrahepatic biliary system: physiological distribution and pathological significance. Prog. Histochem. Cytochem. 42 (2007) 61-110.

[78] K.S. Suh, S.H. Chang, H.J. Lee, H.R. Roh, S.H. Kim, K.U. Lee, Clinical outcomes and apomucin expression of intrahepatic cholangiocarcinoma according to gross morphology. J. Am. Coll. Surg. 195 (2002) 782-789.

[79] M. Higashi, S. Yonezawa, J.J. Ho, et al., Expression of MUC1 and MUC2 mucin antigens in intrahepatic bile duct tumors: its relationship with a new morphological classification of cholangiocarcinoma. Hepatology 30 (1999) 1347-1355.

[80] Y. Imoto, N. Muguruma, T. Kimura, et al., Relationship between mucin expression and preoperative bile juice cytology in biliary tract carcinoma. J. Med. Invest. 54 (2007) 41-47.

[81] W.R. Matull, F. Andreola, A. Loh, et al., MUC4 and MUC5AC are highly specific tumour-associated mucins in biliary tract cancer. Br. J. Cancer 98 (2008) 1675-1681.

[82] T. Yamato, M. Sasaki, Y. Watanabe, Y. Nakanuma, Expression of MUC1 and MUC2 mucin core proteins and their messenger RNA in gall bladder carcinoma: an immunohistochemical and in situ hybridization study. J. Pathol. 188 (1999) 30-37.

[83] S.S. Lee, M.H. Kim, S.K. Lee, et al., Clinicopathologic review of 58 patients with biliary papillomatosis. Cancer 100 (2004) 783-793.

[84] S. Amaya, M. Sasaki, Y. Watanabe, et al., Expression of MUC1 and MUC2 and carbohydrate antigen Tn change during malignant transformation of biliary papillomatosis. Histopathology 38 (2001) 550-560.

[85] E. Leteurtre, G. Piessen, S. Aubert, et al., Mucins as diagnostic and/or prognostic factors in epithelial cancers. in: I. Van Seuningen (Ed.), The Epithelial Mucins: Structure/Function. Roles in Cancer and Inflammatory Diseases. Research Signpost, Kerala, India, 2008, pp. 273-294.

[86] C. Sotiriou, M.J. Piccart, Taking gene-expression profiling to the clinic: when will molecular signatures become relevant to patient care? Nat. Rev. Cancer 7 (2007) 545-553.

[87] J.R. Nevins, A. Potti, Mining gene expression profiles: expression signatures as cancer phenotypes. Nat. Rev. Genet. 8 (2007) 601-609.

[88] R. Kuick, D.E. Misek, D.J. Monsma, et al., Discovery of cancer biomarkers through the use of mouse models. Cancer Lett. 249 (2007) 40-48.

[89] C.K. Tang, V. Apostolopoulos, Strategies used for MUC1 immunotherapy: preclinical studies. Expert Rev. Vaccines 7 (2008) 951-962.

[90] C.K. Tang, M. Katsara, V. Apostolopoulos, Strategies used for MUC1 immunotherapy: human clinical studies. Expert Rev. Vaccines 7 (2008) 963-975

[91] R.Q. Wang, D.C. Fang, Alterations of MUC1 and MUC3 expression in gastric carcinoma: relevance to patient clinicopathological features. J. Clin. Pathol. 56 (2003) 378-384

[92] S. Yonezawa, A. Nakamura, M. Horinouchi, E. Sato, The expression of severa types of mucin is related to the biological behavior of pancreatic neoplasms. J. Hepatobiliary Pancreat. Surg. 9 (2002) 328-341.

[93] S.C. Chauhan, A.P. Singh, F. Ruiz, et al., Aberrant expression of MUC4 in ovarian carcinoma: diagnostic significance alone and in combination with MUC1 and MUC16 (CA125). Mod. Pathol. 19 (2006) 1386-1394.

[94] S. Takao, K. Uchikura, S. Yonezawa, H. Shinchi, T. Aikou, Mucin core protein expression in extrahepatic bile duct carcinoma is associated with metastases to the liver and poor prognosis. Cancer 86 (1999) 1966-1975.

[95] H. Shibahara, S. Tamada, M. Higashi, et al., MUC4 is a novel prognostic factor of intrahepatic cholangiocarcinoma-mass forming type. Hepatology 39 (2004) 220-229.

[96] D.T. Weed, C. Gomez-Fernandez, J. Pacheco, et al., MUC4 and ERBB2 expression in major and minor salivary gland mucoepidermoid carcinoma. Head Neck 26 (2004) 353-364.

[97] D.T. Weed, C. Gomez-Fernandez, M. Yasin, et al., MUC4 and ErbB2 expression in squamous cell carcinoma of the upper aerodigestive tract: correlation with clinical outcomes. Laryngoscope 114 (2004) 1-32.

[98] R.L. Giuntoli 2nd, G.C. Rodriguez, R.S. Whitaker, R. Dodge, J.A. Voynow, Mucin gene expression in ovarian cancers. Cancer Res. 58 (1998) 5546-5550.

[99] K. Llinares, F. Escande, S. Aubert, et al., Diagnostic value of MUC4 immunostaining in distinguishing epithelial mesothelioma and lung adenocarcinoma. Mod. Pathol. 17 (2004) 150-157.

[100] M. Abe, J. Siddiqui, D. Kufe, Sequence analysis of the 5' region of the human DF3 breast carcinoma-associated antigen gene. Biochem. Biophys. Res. Commun. 165 (1989) 644-649.

[101] M. Abe, D. Kufe, Characterization of cis-acting elements regulating transcription of the human DF3 breast carcinoma-associated antigen (MUC1) gene. Proc. Natl. Acad. Sci. U S A 90 (1993) 282-286. 
[102] I.C. Gaemers, H.L. Vos, H.H. Volders, S.W. van der Valk, J. Hilkens, A statresponsive element in the promoter of the episialin/MUC1 gene is involved in its overexpression in carcinoma cells. J. Biol. Chem. 276 (2001) 6191-6199.

[103] A. Kovarik, N. Peat, D. Wilson, S.J. Gendler, J. Taylor-Papadimitriou, Analysis of the tissue-specific promoter of the MUC1 gene. J. Biol. Chem. 268 (1993) 9917-9926.

[104] A. Kovarik, P.J. Lu, N. Peat, J. Morris, J. Taylor-Papadimitriou, Two GC boxes ( $\mathrm{Sp} 1$ sites) are involved in regulation of the activity of the epitheliumspecific MUC1 promoter. J. Biol. Chem. 271 (1996) 18140-18147.

[105] K.L. Nelson, N.A. Becker, G.S. Pahwa, M.A. Hollingsworth, L.J. Maher 3rd, Potential for H-DNA in the human MUC1 mucin gene promoter. J. Biol. Chem. 271 (1996) 18061-18067.

[106] G.S. Pahwa, L.J. Maher 3rd, M.A. Hollingsworth, A potential H-DNA element in the MUC1 promoter does not influence transcription. J. Biol. Chem. 271 (1996) 26543-26546.

[107] M.A. Hollingsworth, C. Closken, A. Harris, C.D. McDonald, G.S. Pahwa L.J. Maher 3rd, A nuclear factor that binds purine-rich, single-stranded oligonucleotides derived from S1-sensitive elements upstream of the CFTR gene and the MUC1 gene. Nucleic Acids Res. 22 (1994) 1138-1146.

[108] C.D. McDonald, M.A. Hollingsworth, L.J. Maher 3rd, Enzymatic and chemical probing of an S1 nuclease-sensitive site upstream from the human CFTR gene. Gene 150 (1994) 267-274.

[109] J.Z. Zaretsky, R. Sarid, Y. Aylon, L.A. Mittelman, D.H. Wreschner, I. Keydar Analysis of the promoter of the MUC1 gene overexpressed in breast cancer. FEBS Lett. 461 (1999) 189-195.

[110] M.C. Abba, M.I. Nunez, A.G. Colussi, M.V. Croce, A. Segal-Eiras, C.M. Aldaz, GATA3 protein as a MUC1 transcriptional regulator in breast cancer cells. Breast Cancer Res. 8 (2006) R64.

[111] T. Irimura, A.M. McIsaac, D.A. Carlson, et al., Soluble factor in normal tissues that stimulates high-molecular-weight sialoglycoprotein production by human colon carcinoma cells. Cancer Res. 50 (1990) 3331-3338.

[112] K. Shirotani, J. Taylor-Papadimitriou, S.J. Gendler, T. Irimura, Transcriptional regulation of the MUC1 mucin gene in colon carcinoma cells by a soluble factor. Identification of a regulatory element. J. Biol. Chem. 269 (1994) 15030-15035.

[113] T. Koga, I. Kuwahara, E.P. Lillehoj, et al., TNF-alpha induces MUC1 gene transcription in lung epithelial cells: its signaling pathway and biological implication. Am. J. Physiol. Lung Cell Mol. Physiol. 293 (2007) L693-L701.

[114] S. Aubert, V. Fauquette, B. Hemon, et al., MUC1, a new hypoxia inducible factor target gene, is an actor in clear renal cell carcinoma tumor progression. Cancer Res. 69 (2009) 5707-5715.

[115] N. Peat, S.J. Gendler, N. Lalani, T. Duhig, J. Taylor-Papadimitriou, Tissuespecific expression of a human polymorphic epithelial mucin (MUC1) in transgenic mice. Cancer Res. 52 (1992) 1954-1960.

[116] R.A. Graham, J.R. Morris, E.P. Cohen, J. Taylor-Papadimitriou, Up-regulation of MUC1 in mammary tumors generated in a double-transgenic mouse expressing human MUC1 CDNA, under the control of 1.4-kb 5' MUC1 promoter sequence and the middle T oncogene, expressed from the MMTV promoter. Int. J. Cancer 92 (2001) 382-387.

[117] A. Vincent, I. Van Seuningen, Mucins, epigenetics and cancer. in: I. Van Seuningen (Ed.), The Epithelial Mucins: Structure/Function. Roles in Cancer and Inflammatory Diseases. Research Signpost, Kerala, India, 2008, pp. 95-108.

[118] S. Zrihan-Licht, M. Weiss, I. Keydar, D.H. Wreschner, DNA methylation status of the MUC1 gene coding for a breast-cancer-associated protein. Int J. Cancer 62 (1995) 245-251.

[119] A.P. Singh, S.C. Chauhan, S. Bafna, et al., Aberrant expression of transmembrane mucins, MUC1 and MUC4, in human prostate carcinomas. Prostate 66 (2006) 421-429.

[120] N. Yamada, Y. Nishida, H. Tsutsumida, et al., MUC1 expression is regulated by DNA methylation and histone $\mathrm{H} 3$ lysine 9 modification in cancer cells. Cancer Res. 68 (2008) 2708-2716.

[121] M. Perrais, P. Pigny, M.P. Ducourouble, et al., Characterization of human mucin gene MUC4 promoter: importance of growth factors and proinflammatory cytokines for its regulation in pancreatic cancer cells. J. Biol. Chem. 276 (2001) 30923-30933.

[122] R.J. Gumina, N.E. Kirschbaum, K. Piotrowski, P.J. Newman, Characterization of the human platelet/endothelial cell adhesion molecule- 1 promoter: identification of a GATA-2 binding element required for optimal transcriptional activity. Blood 89 (1997) 1260-1269.

[123] L. Weis, D. Reinberg, Accurate positioning of RNA polymerase II on a natural TATA-less promoter is independent of TATA-binding-protein-associated factors and initiator-binding proteins. Mol. Cell Biol. 17 (1997) 2973-2984.

[124] M. Yu, X.Y. Yang, T. Schmidt, Y. Chinenov, R. Wang, M.E. Martin, GA-binding protein-dependent transcription initiator elements. Effect of helical spacing between polyomavirus enhancer a factor 3(PEA3)/Ets-binding sites on initiator activity. J. Biol. Chem. 272 (1997) 29060-29067.

[125] M. Karin, A. Haslinger, H. Holtgreve, G. Cathala, E. Slater, J.D. Baxter, Activation of a heterologous promoter in response to dexamethasone and cadmium by metallothionein gene 5'-flanking DNA. Cell 36 (1984) 371-379.
[126] T. Oikawa, T. Yamada, Molecular biology of the Ets family of transcription factors. Gene 303 (2003) 11-34.

[127] V. Fauquette, M. Perrais, S. Cerulis, et al., The antagonistic regulation of human MUC4 and ErbB-2 genes by the Ets protein PEA3 in pancreatic cancer cells: implications for the proliferation/differentiation balance in the cells. Biochem. J. 386 (2005) 35-45.

[128] M. Andrianifahanana, A.P. Singh, C. Nemos, et al., IFN-gamma-induced expression of MUC4 in pancreatic cancer cells is mediated by STAT-1 upregulation: a novel mechanism for IFN-gamma response. Oncogene 26 (2007) 7251-7261.

[129] R.J. Akhurst, R. Derynck, TGF-beta signaling in cancer-a double-edged sword. Trends Cell Biol. 11 (2001) S44-S51.

[130] N. Jonckheere, M. Perrais, C. Mariette, et al., A role for human MUC4 mucin gene, the ErbB2 ligand, as a target of TGF-beta in pancreatic carcinogenesis. Oncogene 23 (2004) 5729-5738.

[131] A. Choudhury, R.K. Singh, N. Moniaux, T.H. El-Metwally, J.P. Aubert, S.K. Batra, Retinoic acid-dependent transforming growth factor-beta 2-mediated induction of MUC4 mucin expression in human pancreatic tumor cells follows retinoic acid receptor-alpha signaling pathway. J. Biol. Chem. 275 (2000) 33929-33936.

[132] M. Andrianifahanana, A. Agrawal, A.P. Singh, et al., Synergistic induction of the MUC4 mucin gene by interferon-gamma and retinoic acid in human pancreatic tumour cells involves a reprogramming of signalling pathways. Oncogene 24 (2005) 6143-6154.

[133] R. McWilliams, W.E. Highsmith, K.G. Rabe, et al., Cystic fibrosis transmembrane regulator gene carrier status is a risk factor for young onset pancreatic adenocarcinoma. Gut 54 (2005) 1661-1662.

[134] A.P. Singh, S.C. Chauhan, M. Andrianifahanana, et al., MUC4 expression is regulated by cystic fibrosis transmembrane conductance regulator in pancreatic adenocarcinoma cells via transcriptional and post-translational mechanisms. Oncogene 26 (2007) 30-41.

[135] M.P. Buisine, L. Devisme, T.C. Savidge, et al., Mucin gene expression in human embryonic and fetal intestine. Gut 43 (1998) 519-524.

[136] M.P. Buisine, N. Porchet, I. Van Seuningen, Mucin expression and regulation during development and cell differentiation. in: I. Van Seuningen (Ed.), The Epithelial Mucins: Structure/Function. Roles in Cancer and Inflammatory Diseases. Research Signpost, Kerala, India, 2008, pp. 75-94.

[137] N. Jonckheere, A. Vincent, M. Perrais, et al., The human mucin MUC4 is transcriptionally regulated by caudal-related homeobox, hepatocyte nuclear factors, forkhead box A, and GATA endodermal transcription factors in epithelial cancer cells. J. Biol. Chem. 282 (2007) 22638-22650.

[138] A. Vincent, M.P. Ducourouble, I. Van Seuningen, Epigenetic regulation of the human mucin gene MUC4 in epithelial cancer cell lines involves both DNA methylation and histone modifications mediated by DNA methyltransferases and histone deacetylases. FASEB J. 22 (2008) 3035-3045.

[139] N. Yamada, Y. Nishida, H. Tsutsumida, et al., Promoter CpG methylation in cancer cells contributes to the regulation of MUC4. Br. J. Cancer 100 (2009) 344-351.

[140] J.R. Gum Jr., J.W. Hicks, S.C. Crawley, et al., Initiation of transcription of the MUC3A human intestinal mucin from a TATA-less promoter and comparison with the MUC3B amino terminus. J. Biol. Chem. 278 (2003) 49600-49609.

[141] C.Y. Ren, Y. Akiyama, S. Miyake, Y. Yuasa, Transcription factor GATA-5 selectively up-regulates mucin gene expression. J. Cancer Res. Clin. Oncol. 130 (2004) 245-252.

[142] V. Lievin-Le Moal, G. Huet, J.P. Aubert, et al., Activation of mucin exocytosis and upregulation of MUC genes in polarized human intestinal mucinsecreting cells by the thiol-activated exotoxin listeriolysin O. Cell Microbiol. 4 (2002) 515-529.

[143] C.J. Tsai, R. Herrera-Goepfert, R.J. Tibshirani, et al., Changes of gene expression in gastric preneoplasia following Helicobacter pylori eradication therapy. Cancer Epidemiol. Biomarkers Prev. 15 (2006) 272-280.

[144] Y. Hori, S.J. Spurr-Michaud, C.L. Russo, P. Argueso, I.K. Gipson, Effect of retinoic acid on gene expression in human conjunctival epithelium: secretory phospholipase A2 mediates retinoic acid induction of MUC16. Invest. Ophthalmol. Vis. Sci. 46 (2005) 4050-4061.

[145] K.Y. Seo, S.H. Chung, J.H. Lee, M.Y. Park, E.K. Kim, Regulation of membraneassociated mucins in the human corneal epithelial cells by dexamethasone. Cornea 26 (2007) 709-714.

[146] K. Ohuchida, K. Mizumoto, D. Yamada, et al., Quantitative analysis of MUC1 and MUC5AC mRNA in pancreatic juice for preoperative diagnosis of pancreatic cancer. Int. J. Cancer 118 (2006) 405-411.

[147] N. Jhala, D. Jhala, S.M. Vickers, et al., Biomarkers in Diagnosis of pancreatic carcinoma in fine-needle aspirates. Am. J. Clin. Pathol. 126 (2006) 572-579.

[148] J. Klapman, M.P. Malafa, Early detection of pancreatic cancer: why, who, and how to screen. Cancer Control 15 (2008) 280-287.

[149] V. Ambros, The functions of animal microRNAs. Nature 431 (2004) 350-355.

[150] I. Van Seuningen, A. Vincent, Mucins: a new family of epigenetic biomarkers in epithelial cancers. Expert Opin. Med. Diagn. 3 (2009) 411-427. 